\title{
CONSERVAÇÃO E TESTE DE TETRAZÓLIO EM SEMENTES DE JABUTICABEIRA ${ }^{1}$
}

\author{
CRISTIANO HÖSSEL ${ }^{2}$, JÉSSICA SCARLET MARTH ALVES DE OLIVEIRA ${ }^{3}$, \\ KELI CRISTINA FABIANE ${ }^{4}$, AMÉRICO WAGNER JÚNIOR ${ }^{5}$, IDEMIR CITADIN ${ }^{6}$
}

RESUMO: O objetivo deste trabalho foi avaliar embalagem a vácuo e biofilme sobre a viabilidade de sementes de jabuticabeira [Plinia trunciflora (O. Berg) Kausel], bem como verificar a aplicabilidade do teste de tetrazólio em sementes dessa espécie. O experimento foi realizado no Laboratório de Fisiologia Vegetal e na Unidade de Ensino e Pesquisa Viveiro de Produção de Mudas Hortícolas, da Universidade Tecnológica Federal do Paraná - Câmpus Dois Vizinhos. O experimento foi em blocos ao acaso, em fatorial 2 (utilização de vácuo) x 3 (tipo de revestimento) x 5 (tempo de armazenamento), com quatro repetições de 50 sementes por unidade experimental. As sementes, após extraídas, foram separadas em dois lotes, sendo um para uso de embalagem a vácuo e outro não. A partir de cada lote, houve a divisão em três sublotes de acordo com o tipo de revestimento, quais sejam: fécula de mandioca $\left(3 \% \mathrm{~m} \mathrm{v}^{-1}\right)$, quitosana $\left(3 \% \mathrm{~m} \mathrm{v}^{-1}\right)$ e sem biofilme. Posteriormente, as sementes foram armazenadas em câmara fria, utilizando temperatura de $5 \pm 1{ }^{\circ} \mathrm{C}$, por 7 ; 14;21; 28 e 35 dias. Foram analisadas as porcentagens de emergência, de viabilidade das sementes pelo teste de tetrazólio e o índice de velocidade de emergência. Recomenda-se armazenar as sementes de jabuticabeira em embalagem a vácuo. Na impossibilidade de utilizar embalagem a vácuo, as sementes desta fruteira devem ser revestidas com biofilme à base de quitosana ou fécula de mandioca. O teste de tetrazólio demonstrou-se viável e mais rápido para avaliar a viabilidade das sementes de jabuticabeira.

Termos de indexação: Myrtaceae, Plinia sp., viabilidade.

\section{CONSERVATION AND TETRAZOLIUM TEST IN JABUTICABA SEEDS}

ABSTRACT - The aim of this study was to evaluate the vacuum packing and biofilms in the viability seeds of jabuticaba tree [Plinia trunciflora (O. Berg) Kausel], as well as, verify if the tetrazolium "test" can be applied in these seeds. The experiment was carried out at the Plant Physiology Laboratory and in the Nursery at the Universidade Tecnológica Federal do Paraná - Câmpus Dois Vizinhos, State of Paraná, Brazil. The experimental design was randomized blocks, in factorial 2 (vacuum use) x 3 (coating type) x 5 (storage time), with four replication of fifty seed by plot. The seeds were extracted and it was separate in two lots, one to use for the vacuum packing and the other not. Each lot was separated in three sub-lots according to the coating type [ cassava starch $\left(3 \% \mathrm{~m} \mathrm{v}^{-1}\right)$, chitosan $\left(3 \% \mathrm{~m} \mathrm{v}^{-1}\right)$ and without biofilm]. Then, the seeds were stored in cold chamber using constant temperature of $5 \pm 1{ }^{\circ} \mathrm{C}$ for $7,14,21,28$ and 35 days. The emergence percentage, seed viability by the tetrazolium "test" and emergence speed index were evaluated. It was recommended to store the jabuticaba seeds in vacuum packing. If it is not possible to use de vacuum packing, the jabuticaba seeds should be coated with biofilm-based chitosan or cassava starch. The tetrazolium "test" proved to be feasible and faster to evaluate the jabuticaba seeds viability.

Index terms: Myrtaceae, Plinia sp., viability.

\footnotetext{
'(Trabalho 180-12). Recebido em: 06-06-2012. Aceito para publicação em: 25-01-2013.

${ }^{2}$ Acadêmico do curso de Engenharia Florestal. Universidade Tecnológica Federal do Paraná (UTFPR) - Câmpus Dois Vizinhos. E-mail: cris_tiano26@hotmail.com. Bolsista CNPq.

${ }^{3}$ Acadêmico do curso de Zootecnia. UTFPR - Câmpus Dois Vizinhos. Bolsista Fundação Araucária. E-mail: jeh.alves93@hotmail.com ${ }^{4}$ Bióloga. M.a. Instituto Federal de Santa Catarina - Câmpus São Miguel do Oeste. E-mails: kelicristinafabiane@yahoo.com ${ }^{5}$ Eng. Agr. Dr. Professor. UTFPR - Câmpus Dois Vizinhos, Dois Vizinhos - PR. E-mails: americowagner@utfpr.edu.br. Tutor Grupo PET - Conexão dos Saberes - Agricultura Familiar - Saberes e Fazeres da Vida no Campo.

${ }^{6}$ Eng. Agr. Dr. Professor. UTFPR - Câmpus Pato Branco, Pato Branco - PR. E-mail: idemir@utfpr.edu.br.
} 


\section{INTRODUÇÃO}

A jabuticabeira é fruteira nativa do Brasil, pertencente à família Myrtaceae e ao gênero Plinia, tendo nove espécies conhecidas, entre as quais se destacam $P$. trunciflora Berg, conhecida como jabuticaba de cabinho; P. cauliflora (DC) Berg, como jabuticaba paulista ou jabuticaba-açu, e P. jaboticaba (Vell.) Berg, como jabuticaba Sabará, sendo esta a mais comercializada no mercado brasileiro (DANNER et al., 2011a). A potencialidade econômica desta espécie abrange o mercado de frutos in natura ou industrializados na forma de bebidas, geleias, doces, sorvetes, picolés, entre outras formas de uso (RUFINO, 2008).

Todavia, ainda são inexistentes os pomares comerciais desta fruteira nativa, prevalecendo o extrativismo, o que demonstra a necessidade da implantação dos mesmos para alavancar essa potencialidade.

Para isto, torna-se necessária a criação de programas de melhoramento, com a criação de bancos de germoplasma que permitam selecionar genótipos dentro de cada espécie com grande potencialidade para cultivo comercial.

Neste sentido, o uso de sementes para introdução de materiais promissores torna-se vantajoso para jabuticabeira, uma vez que possuem a característica da poliembrionia, permitindo-se obter mais de uma plântula por semente e algumas serem geneticamente idênticas à planta-mãe.

Contudo, uma das dificuldades para a introdução de materiais promissores em programas de melhoramento deve-se ao fato de as sementes de jabuticabeira serem classificadas como recalcitrantes, não tolerando dessecação, o que inviabiliza a conservação da viabilidade pelos métodos convencionais de armazenamento, que têm como pressupostos básicos a secagem e o armazenamento em baixas temperaturas.

De acordo com Ambrósio et al. (2008), a partir de dez dias de extração, as sementes de jabuticabeira perdem totalmente a viabilidade, devido a seu teor de umidade estar abaixo de $13 \%$.

Além disso, mesmo que as sementes fossem armazenadas sob elevada umidade relativa e baixa temperatura, supõe-se que não se pode conservá-las por tempo maior, pois, nestes casos, há a possibilidade de ocorrer sua germinação quando armazenadas, bem como de serem contaminadas por fungos, comprometendo a sobrevivência de todo um lote (BONJOVANI;BARBEDO, 2008; FIOR et al., 2010).

Uma alternativa para a conservação das sementes recalcitrantes poderia ser por meio do uso de biofilmes revestindo-as, uma vez que a camada exterior formada pelo biofilme forneceria proteção a danos mecânicos e à penetração de patógenos, bem como regularia a saída de água e oxigênio necessários para maior conservação (BATISTA et al., 2005).

$\mathrm{Na}$ literatura, há poucas informações sobre os métodos de armazenamento de sementes de jabuticabeira, sendo necessária a criação de metodologia adequada para permitir a conservação destas sem que ocorram impactos sobre sua viabilidade.

Em decorrência dessa constatação, para que se possa conseguir um método adequado para armazenar as sementes recalcitrantes, é necessário que sejam realizados testes com diferentes umidades relativas e temperaturas. Entretanto, para a realização destes testes, é necessário que a avaliação da viabilidade das sementes seja rápida e confiável.

Normalmente, os testes de germinação e vigor preconizados pelos laboratórios de análises de sementes demandam tempo para sua aplicação e, no caso da jabuticabeira, não existe ainda protocolo dentro da Regra de Análise de Sementes (BRASIL, 2009).

Um teste rápido e promissor para a avaliação da viabilidade de sementes é o teste de tetrazólio, que permite determinar a viabilidade e o vigor das sementes em, no máximo, 48 horas (BHERING, et al., 2005). Além disso, o teste de tetrazólio ainda apresenta como vantagens, se comparado ao teste de germinação, a avaliação do embrião individualmente em cada semente, sem ter interferências em seus resultados finais, como a presença de patógenos, como os fungos (CERVI;MENDONÇA, 2009).

Assim, com o objetivo de se conseguir uma forma rápida e confiável de verificar a viabilidade das sementes de jabuticabeira, bem como uma maneira de conservá-las, desenvolveu-se a presente pesquisa que avalia o uso da embalagem a vácuo e de biofilmes sobre a viabilidade de sementes de jabuticaba, assim como determinar a adequabilidade do teste de tetrazólio para a determinação de sua viabilidade.

\section{MATERIAL E MÉTODOS}

O experimento foi realizado no Laboratório de Fisiologia Vegetal e na Unidade de Ensino e Pesquisa, Viveiro de Produção de Mudas Hortícolas, da Universidade Tecnológica Federal do Paraná (UTFPR), Câmpus Dois Vizinhos.

Foram utilizadas sementes de jabuticabeira [Plinia trunciflora (O. Berg) Kausel] obtidas de frutos maduros (coloração da epiderme atropurpúrea) (ALEXANDRE et al., 2006). Para a extração 
das sementes, foi realizado o amassamento manual dos frutos contra uma superfície plana e firme de uma bancada, de modo que sua casca rompesse e expusesse suas sementes. A mucilagem foi retirada manualmente, por meio de fricção em peneira de malha fina, acrescentando cal virgem. Após a remoção da mucilagem, as sementes foram lavadas em água corrente e dispostas sobre papel-toalha, onde permaneceram durante 24 horas à sombra, para eliminar 0 excesso de umidade.

Em seguida, as sementes foram separadas em dois lotes, sendo um para uso de embalagem a vácuo e outro sem embalagem a vácuo. A partir de cada lote, houve a divisão deste, em três sublotes de acordo com o tipo de revestimento, sendo estes: fécula de mandioca ( $\left.3 \% \mathrm{~m} \mathrm{v}^{-1}\right)$, quitosana $\left(3 \% \mathrm{~m} \mathrm{v}^{-1}\right)$ e sem biofilme.

Posteriormente, as sementes foram armazenadas em câmara fria, com temperatura constante de $5^{\circ} \mathrm{C} \pm 1^{\circ} \mathrm{C}$ por cinco períodos, de 7 ; $14 ; 21 ; 28$ e 35 dias. Após cada período, as sementes foram semeadas em tubetes pequenos, redondos e individuais $\left(50 \mathrm{~cm}^{3}\right)$, contendo substrato composto por Latossolo Vermelho e areia $(1: 1 \mathrm{v} / \mathrm{v})$ como substrato. Na sequência, os tubetes com as sementes foram acondicionados em casa de vegetação.

Foi realizado irrigação por aspersão em dois turnos diários (no início da manhã e no final da tarde), sempre verificando previamente a umidade do substrato, por um período de 30 a 40 minutos.

$\mathrm{O}$ delineamento experimental foi em blocos ao acaso, no esquema fatorial 2 (utilização de vácuo) x 3 (tipo de revestimento) x tempo de armazenamento), com quatro repetições de 50 sementes por unidade experimental.

Foram avaliados as porcentagens de emergência, de viabilidade das sementes e o índice de velocidade de emergência das mesmas (IVE) (do décimo oitavo dia até o centésimo dia, contados a partir da semeadura).

Para análise da viabilidade das sementes, em cada período, foram retirados quatro lotes de 100 sementes por tratamento, submetendo-as ao teste de tetrazólio, seguindo-se as recomendações de Brasil (2009), para eucalipto, uma vez que essa espécie também se trata de uma Mirtácea, identificando-se as sementes viáveis e não viáveis. Para o teste de visibilidade, foi utilizada solução de cloreto de 2 , 3, 5 trifenil tetrazólio cloreto, na concentração de $1 \%$, sendo realizados cortes longitudinal e diagonal, evitando-se atingir o eixo embrionário. As sementes foram colocadas em câmara úmida, durante 24 horas, a $20^{\circ} \mathrm{C}$, entre papel germitest umedecido, em seguida as mesmas foram segmentadas no sentido longitudinal ao embrião, e colocadas com a parte cortada em contato com a solução de tetrazólio (caixas gerbox contendo papel germitest, umedecido com $6 \mathrm{~mL}$ da solução de tetrazólio), onde permaneceram por um período de 24 horas, a $25^{\circ} \mathrm{C}$ e na ausência de luz.

Os dados das variáveis avaliadas foram previamente submetidos ao teste de normalidade de Lilliefors, constando-se a necessidade da transformação para emergência e viabilidade, e IVE. As transformações foram efetuadas por meio do arco-seno raiz de $\mathrm{x} / 100$ e raiz quadrada de $\mathrm{x}+1$ para emergência e viabilidade, e IVE, respectivamente. Com a transformação dos dados, os mesmos foram submetidos à análise de variância e ao teste de Duncan $(p \leq 0,05)$, com uso do programa Genes (CRUZ, 2001).

Realizou-se a análise de correlação de Pearson entre os dados obtidos pelo teste de tetrazólio (\% de sementes viáveis) com o de sementes emergidas.

\section{RESULTADOS E DISCUSSÃO}

Os resultados obtidos indicam que houve interação significativa entre utilização de vácuo $\mathrm{x}$ tipo de revestimento para emergência de plântulas (Tabela 1), bem como entre utilização de vácuo e tempo de armazenamento para emergência e IVE (Tabelas $2 \mathrm{e}$ 3 , respectivamente). Para essa última variável (IVE), também houve efeito significativo para o fator tipo de revestimento (Tabela 4).

Para o teste de tetrazólio, houve interação significativa entre a utilização de vácuo $\mathrm{x}$ tempo de armazenamento (Tabela 5) e tempo de armazenamento e tipo de revestimento (Tabela 6). As demais interações não apresentaram significância para a viabilidade das sementes de jabuticabeira.

Na Tabela 1, com o uso da embalagem a vácuo, obteve-se maior emergência de plântulas, independentemente do tipo de revestimento utilizado. Contudo, analisando-se somente o uso de embalagem a vácuo, verificou-se que não há necessidade de revestimento das sementes de jabuticabeira, uma vez que todas as médias foram estatisticamente semelhantes entre si. Por outro lado, o mesmo não pode ser aplicado quando não se utiliza embalagem a vácuo, uma vez que as maiores médias para emergência das plântulas foram obtidas utilizandose do revestimento das sementes com fécula de mandioca e quitosana.

Isso pode ter ocorrido pelo fato de que o vácuo retira a quantidade de oxigênio, diminuindo-se a atividade metabólica das sementes armazenadas, o que proporciona menor consumo de energia durante 
o período em que permaneceram conservadas, o que torna maior o tempo de viabilidade das mesmas.

Danner et al. (2011b), procurando prolongar a viabilidade das sementes de jabuticabeira, testaram diferentes condições de armazenamento (vácuo a seco, com água e com tampão fosfato $\mathrm{pH} 7,0$ ), concluindo que o vácuo, juntamente com o tampão fosfato, manteve razoavelmente a viabilidade das sementes por até 65 dias.

No presente experimento, o uso do vácuo a seco permitiu que as sementes permanecessem viáveis por até 28 dias, diferentemente de Danner et al. (2011b) com Plinia cauliflora, o que pode ser decorrente da espécie de jabuticabeira estudada em cada pesquisa.

Quanto ao tempo de armazenamento das sementes, verificou-se que as maiores médias de emergência de plântulas foram obtidas quando as mesmas permaneceram por $14 ; 21$ e 28 dias em embalagem a vácuo (Tabela 2), sendo o mesmo obtido com o vácuo aos $21 ; 28$ e 35 dias para o IVE (Tabela 3 ). Para as sementes não embaladas a vácuo, as maiores médias de emergência de plântulas e IVE foram nos períodos de 7 e 14 dias de armazenamento (Tabelas 2 e 3 , respectivamente).

As sementes armazenadas em embalagem a vácuo foram superiores estatisticamente àquelas mantidas sem vácuo para emergência de plântulas durante os períodos de $14 ; 21 ; 28$ e 35 dias, igualando-se somente aos 7 dias (Tabela 2). Este mesmo resultado estatístico, comparando-se as sementes não embaladas com aquelas embaladas a vácuo, foi obtido com esta interação no IVE (Tabela 3) e na análise da viabilidade das sementes submetidas ao teste tetrazólio (Tabela 5).
O comportamento observado comprova o efeito benéfico do uso da embalagem a vácuo sobre as sementes de jabuticabeira, permitindo obter também além da emergência maior vigor das sementes.

Porém, é importante ressaltar que o uso do vácuo deve ser utilizado com cuidado, uma vez que Freitas et al. (2011), testando o armazenamento a vácuo de sementes de ipê-verde sob diferentes condições de pressão $(200 ; 400$ e $600 \mathrm{~mm}$ de $\mathrm{Hg}$ ), durante 2; 4 e 6 meses, observaram que as pressões entre 200 e $400 \mathrm{~mm}$ de $\mathrm{Hg}$ aumentaram significativamente o percentual de plantas anormais, assim como o de plantas danificadas.

Quanto ao tipo de revestimento, as sementes de jabuticabeira revestidas com fécula de mandioca e quitosana apresentaram valores superiores estatisticamente aos das sementes sem biofilmes para o IVE (Tabela 5). Com ambos os biofilmes (fécula de mandioca e quitosana), conseguiu-se manter as sementes viáveis até 14 dias, em comparação às sem revestimento, segundo teste de tetrazólio (Tabela 6).

Isto que pode estar vinculado à menor perda de umidade das sementes revestidas, bem como à menor troca gasosa, o que, neste último caso, reduz a atividade metabólica das sementes, permitindo a manutenção de maior quantidade de reservas úteis para provê-las de maior vigor.

Analisando-se a correlação, verifica-se que houve resposta significativa $\left(\mathrm{r}^{2}=0,79 * *\right)$ entre os resultados de emergência das plântulas e de viabilidade das sementes, o que permite recomendar o uso do teste de tetrazólio a $1 \%$ em sementes de jabuticabeira, já que se reduz o tempo de avaliação de sua viabilidade.

TABELA 1- Emergência (\%) de plântulas de jabuticabeira [Plinia trunciflora (O. Berg) Kausel], com e sem o uso de embalagem a vácuo e tipo de revestimento utilizado nas sementes.

\begin{tabular}{ccc}
\hline \multirow{2}{*}{ Revestimento } & \multicolumn{2}{c}{ Embalagem } \\
\cline { 2 - 3 } & Vácuo & Sem vácuo \\
\hline Fécula de mandioca & 54,14 a A* & 11,02 a B \\
Quitosana & 49,36 a A & 14,37 a B \\
Sem revestimento & 57,15 a A & 6,18 b B \\
\hline CV(\%) & \multicolumn{2}{c}{22,96} \\
\hline
\end{tabular}

*Em cada coluna, médias seguidas pela mesma letra minúscula e, em cada linha, pela mesma letra maiúscula não diferem estatisticamente, pelo teste de Duncan $(p \leq 0,05)$. 
TABELA 2 - Emergência (\%) de plântulas de jabuticabeira [Plinia trunciflora (O. Berg) Kausel], com e sem uso de embalagem a vácuo, $7 ; 14 ; 21 ; 28$ e 35 dias de armazenamento das sementes.

\begin{tabular}{crc}
\hline \multirow{2}{*}{ Dias } & \multicolumn{2}{c}{ Embalagem } \\
\cline { 2 - 3 } & Vácuo & Sem vácuo \\
\hline 7 & $43,76 \mathrm{c} \mathrm{A}$ & $40,51 \mathrm{a} \mathrm{A}$ \\
14 & $59,84 \mathrm{a} \mathrm{A}$ & $42,34 \mathrm{a} \mathrm{B}$ \\
21 & $61,53 \mathrm{a} \mathrm{A}$ & $2,41 \mathrm{~b} \mathrm{~B}$ \\
28 & $56,58 \mathrm{ab} \mathrm{A}$ & $0,18 \mathrm{~b} \mathrm{~B}$ \\
35 & $45,94 \mathrm{bc} \mathrm{A}$ & $0,11 \mathrm{~b} \mathrm{~B}$ \\
\hline $\mathbf{C V ( \% )}$ & \multicolumn{3}{c}{22,96} \\
\hline
\end{tabular}

*Em cada coluna, médias seguidas pela mesma letra minúscula e, em cada linha, pela mesma letra maiúscula não diferem estatisticamente, pelo teste de Duncan $(p \leq 0,05)$.

TABELA 3- Índice de velocidade de emergência de plântulas [Plinia trunciflora (O. Berg) Kausel], com e sem uso de embalagem a vácuo, 7; 14;21;28 e 35 dias de armazenamento das sementes.

\begin{tabular}{ccc}
\hline \multirow{2}{*}{ Período de armazenamento } & \multicolumn{2}{c}{ Embalagem } \\
\cline { 2 - 3 } & Vácuo & Sem vácuo \\
\hline 7 & $1,85 \mathrm{~b} \mathrm{~A}$ & $1,69 \mathrm{a} \mathrm{A}$ \\
14 & $1,90 \mathrm{~b} \mathrm{~A}$ & $1,47 \mathrm{a} \mathrm{A}$ \\
21 & $2,72 \mathrm{ab} \mathrm{A}$ & $0,49 \mathrm{~b} \mathrm{~B}$ \\
28 & $2,91 \mathrm{a} \mathrm{A}$ & $0,11 \mathrm{c} \mathrm{B}$ \\
35 & $3,02 \mathrm{a} \mathrm{A}$ & $0,07 \mathrm{c} \mathrm{B}$ \\
\hline $\mathbf{C V}(\%)$ & \multicolumn{2}{c}{31,50} \\
\hline
\end{tabular}

*Em cada coluna, médias seguidas pela mesma letra minúscula e, em cada linha, pela mesma letra maiúscula não diferem estatisticamente, pelo teste de Duncan $(p \leq 0,05)$.

TABELA 4 - Índice de velocidade de emergência (IVE) de jabuticabeira [Plinia trunciflora (O. Berg) Kausel], quanto ao revestimento.

\begin{tabular}{lc}
\hline \multicolumn{1}{c}{ Revestimento } & IVE \\
\hline Fécula de mandioca & $1,53 \mathrm{a}^{*}$ \\
Quitosana & $1,47 \mathrm{a}$ \\
Sem revestimento & $1,10 \mathrm{~b}$ \\
\hline \multicolumn{1}{c}{$\mathbf{C V}(\%)$} & 31,50 \\
\hline
\end{tabular}

"Médias seguidas pela mesma letra não diferem, pelo teste de Duncan $(\mathrm{p} \leq 0,05)$

TABELA 5 - Viabilidade (\%) de sementes de jabuticabeira [Plinia trunciflora (O. Berg) Kausel] com teste de tetrazólio, de acordo com o período de armazenamento e com o uso de embalagem a vácuo e sem vácuo nas sementes.

\begin{tabular}{ccc}
\hline \multirow{2}{*}{$\begin{array}{c}\text { Período de } \\
\text { armazenamento }\end{array}$} & \multicolumn{2}{c}{ Embalagem } \\
\cline { 2 - 3 } & Vácuo & Sem vácuo \\
\hline 7 & $72,03 \mathrm{~b} \mathrm{~A}^{*}$ & $69,20 \mathrm{a} \mathrm{A}$ \\
14 & $88,75 \mathrm{a} \mathrm{A}$ & $43,27 \mathrm{~b} \mathrm{~B}$ \\
21 & $72,94 \mathrm{~b} \mathrm{~A}$ & $19,34 \mathrm{c} \mathrm{B}$ \\
28 & $81,38 \mathrm{ab} \mathrm{A}$ & $8,58 \mathrm{~d} \mathrm{~B}$ \\
35 & $74,77 \mathrm{~b} \mathrm{~A}$ & $1,23 \mathrm{e} \mathrm{B}$ \\
\hline $\mathrm{CV}(\%)$ & \multicolumn{3}{c}{16,63}
\end{tabular}

*Em cada coluna, médias seguidas pela mesma letra minúscula e, em cada linha, pela mesma letra maiúscula não diferem estatisticamente, pelo teste de Duncan $(p \leq 0,05)$. 
TABELA 6- Viabilidade (\%) de sementes de jabuticabeira [Plinia trunciflora (O. Berg) Kausel] de acordo com o período de armazenamento e tipo de revestimento com teste de tetrazólio.

\begin{tabular}{ccc|c}
\hline Período de & \multicolumn{3}{c}{ Revestimento } \\
\cline { 2 - 4 } armazenamento & Fécula de mandioca & Quitosana & Sem revestimento \\
\hline 7 & $71,06 \mathrm{a} \mathrm{AB}$ & $60,23 \mathrm{ab} \mathrm{B}$ & $79,66 \mathrm{a} \mathrm{A}$ \\
14 & $67,45 \mathrm{ab} \mathrm{A}$ & $74,16 \mathrm{a} \mathrm{A}$ & $63,18 \mathrm{~b} \mathrm{~A}$ \\
21 & $56,80 \mathrm{~b} \mathrm{~A}$ & $37,19 \mathrm{c} \mathrm{B}$ & $42,40 \mathrm{~cd} \mathrm{~B}$ \\
28 & $40,23 \mathrm{c} \mathrm{A}$ & $42,27 \mathrm{c} \mathrm{A}$ & $45,29 \mathrm{c} \mathrm{A}$ \\
35 & $28,07 \mathrm{c} \mathrm{A}$ & $31,50 \mathrm{c} \mathrm{A}$ & $29,96 \mathrm{~d} \mathrm{~A}$ \\
\hline $\mathrm{CV}(\%)$ & \multicolumn{3}{|c}{16,63} \\
\hline
\end{tabular}

*Em cada coluna, médias seguidas pela mesma letra minúscula e, em cada linha, pela mesma letra maiúscula não diferem estatisticamente, pelo teste de Duncan $(p \leq 0,05)$.

\section{CONCLUSÃO}

Recomenda-se armazenar as sementes de jabuticabeira [Plinia trunciflora (O. Berg) Kausel] em embalagem a vácuo. Na impossibilidade de armazenar as sementes desta espécie, as sementes devem ser revestidas com biofilme à base de quitosana ou fécula de mandioca. O teste de tetrazólio demonstra-se viável e mais rápido para avaliar a viabilidade das sementes de jabuticabeira.

\section{AGRADECIMENTO}

Ao Conselho Nacional de Desenvolvimento Científico e Tecnológico e à Fundação Araucária, pela concessão das bolsas.

\section{REFERÊNCIAS}

AMBRÓSIO, R.; DANNER, M.A.; CITADIN, I.; SACHET, M.R.; SASSO, S.A.Z.; MEDEIROS, J.G.S. Efeito do período e da temperatura de armazenamento na viabilidade de sementes de jabuticabeira (Plinia cauliflora). In: CONGRESSO BRASILEIRO DE FRUTICULTURA, 20., ANUAL MEETING OF THE INTERAMERICAN SOCIETY FOR TROPICAL HORTICULTURE, 54., 2008. Vitória. Anais... CD-ROM.

ALEXANDRE, R. S.; WAGNER JÚNIOR, A.; NEGREIROS, J. R. S.; BRUCKNER, C. H. Estádio de maturação dos frutos e substratos na germinação de sementes e desenvolvimento inicial de plântulas de jabuticabeira. Revista Brasileira de Agrociência, Pelotas, v. 12, n. 2, p. 227-230, 2006.
BATISTA, J.A.; TANADA-PALMU, P.S.; PASSOS, F.A.; TRANI, P.E.; GROSSO, C.R.F. Vigor de sementes de brócolos submetidas a coberturas biodegradáveis e micronutrientes. Horticultura Brasileira, Brasília, v.23, n.3, p.841-845, 2005.

BHERING, M. C.; DIAS, D. C. F. DOS S.; BARROS, D. I.; Adequação da metodologia do teste de tetrazólio para avaliação da qualidade fisiológica de sementes de melancia. Revista Brasileira de Sementes, Londrina, v. 27, n 1, p.176-182, 2005.

BONJOVANI, M. R.; BARBEDO, C. J. Sementes recalcitrantes: intolerantes a baixas temperaturas? Embriões recalcitrantes de Inga vera Willd. subsp. affinis (DC.) T. D. Penn. toleram temperatura subzero. Revista Brasileira de Botanica, São Paulo, v.31, n.2, p.345-356, 2008.

BRASIL. Regras para análise de sementes. Brasília: Ministério da Agricultura, Pecuária e Abastecimento. Brasília, 2009. 395 p.

CERVI, F.; MENDONÇA, E. A. F.; Adequação do teste de tetrazólio para sementes de algodoeiro. Revista Brasileira de Sementes, Londrina, v. 31, $\mathrm{n}$. 1, p.177-186, 2009.

CRUZ, C.D. Programa genes: aplicativo computacional em genética e melhoramento. 2.ed. Viçosa: UFV, 2001. 648p.

DANNER, M. A.; CITADIN, I.; FERNANDES JUNIOR, A. de A.; ASSMANN, A. P.; MAZARO, S. M.; DONAZZOLO, J.; SASSO, S. A. Z Enraizamento de jabuticabeira (Plinia trunciflora) por mergulhia aérea. Synergismus scyentifica UTFPR, Pato Branco, v.1, n.1/4, p. 197-206. 2006. 
DANNER, M. A.; CITADIN, I.; SASSO, S.A.Z.; AMBrosio, R.; WAGNER JÚNIOR, A. Armazenamento a vácuo prolonga a viabilidade de sementes de jabuticabeira, Revista Brasileira de Fruticultura, Jaboticabal, v. 33, n. 1, p. 246-252, $2011 b$.

DANNER, M.A.; CITADIN, I.; SASSO, S.A.Z.; SACHET, M.R.; MALAGI, G. Modo de reprodução e viabilidade de pólen de três espécies de jabuticabeira. Revista Brasileira de Fruticultura, Jaboticabal, v. 33, n. 2, p. 345-352, 2011 a.

FIOR, C. S.; RODRIGUES, L. R.; CALIL, A. C.; LEONHARDT, C.; de SOUZA, L. dos S.; SILVA, V. S. da; Qualidade fisiológica de sementes de guabijuzeiro (Myrcianthes pungens (Berg) Legrand - Myrtaceae) em armazenamento. Revista Árvore, Viçosa-MG, v. 34, n. 3, p. 435-442, 2010.
FREITAS, M. N.; SANTANA, D. G.; CAMARGO R. de. Conservação de sementes de ipê-verde (Cybistax antisyphilitica Mart.) por armazenamento a vácuo. Revista Verde, Mossoró, v. 6, n. 4, p. 142 - 148, 2011.

RUFINO, M. do S. M. Propriedades funcionais de frutas tropicais brasileiras não tradicionais. 2008. 263f. Tese (Doutorado) -Faculdade de Agronomia, Universidade Federal Rural do SemiÁrido, Mossoró, 2008. 